\title{
Serum Adiponectin Is Associated with Smoking Status in Healthy Korean Men
}

\author{
JAe WoOng SULl, HeE Jin KIM, Ji Eun YUn, Eun Jung PARK*, GRACe KIM** AND Sun Ha JEE \\ Institute for Health Promotion \& Department of Epidemiology and Health Promotion, Graduate School of Public Health, Yonsei \\ University, Seoul, Republic of Korea \\ * Metabolic Syndrome Research Initiatives, Seoul, Republic of Korea \\ **School of Medicine, Johns Hopkins University, Baltimore, MD, USA
}

\begin{abstract}
Objective: To measure the association between smoking and serum adiponectin, taking into consideration insulin resistance and obesity. Material and Methods: The cross-sectional study was carried out in Seoul, Korea in 2006. Waist circumference (WC), body mass index (BMI), and serum adiponectin were measured in 2,500 healthy Korean men. Multiple linear regression models were used to assess the association of smoking status with serum adiponectin level. WC, BMI, and homeostasis model assessment (HOMA) were classified into two groups according to median values. Results: The mean adiponectin concentrations were $6.6 \mu \mathrm{g} / \mathrm{ml}$ and $7.3 \mu \mathrm{g} / \mathrm{ml}$ in current smokers and non-smokers. After adjusting for age, BMI, and alcohol consumption, mean log adiponectin levels decreased by $0.064 \mu \mathrm{g} / \mathrm{ml}$ in current smokers compared with non-smokers $(\mathrm{P}=0.0190)$. Mean log adiponectin levels also decreased by 0.030 and $0.095 \mu \mathrm{g} / \mathrm{ml}$ in moderate and heavy smokers compared to non-smokers. The relationship between adiponectin and smoking was similar between the high and low insulin resistance, BMI, and WC groups. Conclusions: These results suggest that serum adiponectin levels are associated with smoking status. These data also support that lower serum adiponectin concentrations in smokers may not be dependent on insulin resistance status or obesity.
\end{abstract}

Key words: Smoking, Adiponectin, Obesity, Insulin resistance

(Endocrine Journal 56: 73-78, 2009)

\begin{abstract}
ADIPONECTIN has been reported as a new risk factor for the development of diabetes. Exclusively secreted by adipose tissue, adiponectin is a 244 -amino acid protein that regulates the metabolism of lipids and glucose, and circulates quite abundantly in plasma [1-5]. Adiponectin decreases insulin resistance and body weight by increasing lipid oxidation in muscle and in other organs, such as the pancreas and liver [6]. Hotta et al. [7] showed that plasma adiponectin concentrations were reduced among individuals with obesity, diabetes mellitus, or coronary heart disease $[7,8]$, implying that adiponectin plays a role in these conditions.
\end{abstract}

Received: August 25, 2008

Accepted: September 23, 2008

Correspondence to: Sun Ha JEE, M.H.S., Ph.D., Department of Epidemiology and Health Promotion, Graduate School of Public Health, Yonsei University, Seoul, Republic of Korea
Many studies have reported on hypoadiponectinemia in smokers [9-13]. However, the underlying mechanisms of this relationship are not yet fully understood. Because the prevalence of insulin resistance may also be increased in smokers [14, 15], it is not clear whether hypoadiponectinemia in these individuals is due to smoking, or to the coexistence of insulin resistance. However, relevant literature on the relationship between serum adiponectin and smoking status independent of insulin resistance is sparse. Thus, the purpose of this study was to measure the association between smoking and adiponectin, taking into consideration the effects of insulin resistance and obesity. We hypothesized that adiponectin in smokers is associated with smoking status regardless of insulin resistance and obesity. 


\section{Material and Methods}

\section{Study subjects}

The study population consisted of 3,820 male subjects who participated in the Korean Metabolic Syndrome Research Initiative and had routine health examinations at the Health Promotion Center in university hospitals from January to December 2006. The participants who volunteered to undergo the health examinations were informed of the purpose and contents of this research project. Recruitment of these volunteer subjects only took place after their informed consent had been obtained. Participating hospitals are listed in the appendix [16]. The analysis excluded subjects with missing information on waist circumference (WC), body mass index (BMI), or adiponectin levels, and those who had a history of cancer, cardiovascular disease, stroke, diabetes, or hypertension $(n=565)$. We also excluded those who had been on medication for either hypertension or diabetes, and subjects with fasting blood sugar $>110 \mathrm{mg} / \mathrm{dl}$ or hypertension (SBP $\geq 140$ or $\mathrm{DBP} \geq 90 \mathrm{mmHg})(\mathrm{n}=755)$. Finally, 2,500 subjects, aged 24 to 87 years, were selected for subsequent analysis. The Institutional Review Board of Human Research of Yonsei University approved the study, and written informed consent was obtained from all subjects.

\section{Data collection}

Each participant was interviewed using a structured questionnaire to collect history of cigarette smoking (non-smoker, ex-smoker, or current smoker) and alcohol consumption (non-drinker or drinker of any amount of alcohol), as well as other demographic characteristics such as age, gender, and family history of diabetes. Both current and ex-smokers were asked to report the average number of cigarettes they smoke or had smoked per day. WC was measured midway between the lower rib and the iliac crest. Weight and height were measured while the participants were wearing light clothing. BMI was calculated as weight $(\mathrm{kg})$ divided by the square of height $\left(\mathrm{m}^{2}\right)$. Blood pressure was measured with the subject in a seated position by a registered nurse or blood pressure technician using a standard mercury sphygmomanometer or automatic manometer. Both systolic and diastolic blood pressures were measured after a 15 minute rest.

\section{Measurement of biomarkers}

For the clinical chemistry assay, serum was separated from peripheral venous blood sample that was obtained from each participant after 12 hours of fasting, and was stored at $-70^{\circ} \mathrm{C}$ for two hours. Metabolic syndrome biomarkers such as fasting blood glucose, total cholesterol (TC), triglycerides (TG), and high density lipoprotein cholesterol (HDL-C) were measured using the Hitachi-7600 analyzer (Hitachi Ltd., Tokyo, Japan). For subjects with available serum, adiponectin levels were measured using an enzyme-linked immunosorbent assay (Mesdia Co., Ltd., Seoul, Republic of Korea). Insulin resistance was calculated using the homeostasis model assessment of insulin resistance (HOMA-IR). Homeostasis model assessment (HOMA) indices were calculated as follows: HOMA $=$ fasting insulin $(\mu \mathrm{l} \mathrm{U} / \mathrm{ml}) \times$ fasting glucose $(\mathrm{mmol} / \mathrm{l}) / 22.5$. The intra- and inter-assay variances for adiponectin were $6.3 \%$ to $7.4 \%$ and $4.5 \%$ to $8.6 \%$, respectively [16]. Data quality control was performed in accordance with the procedures of the Korean Association of Laboratory Quality Control.

\section{Statistical analyses}

All biomarkers were seen to have a normal distribution except adiponectin. Therefore, $\log$ transformation was used to analyze adiponectin levels. Analysis of variance (ANOVA) was used to analyze the statistical differences among the characteristics of the study participants. Mean of serum adiponectin levels were calculated for each category of smoking status. Multiple linear regression models were used to assess the association of smoking status with serum adiponectin level. Current smokers were further divided into three groups of $1-10,11-20$, and 20 or more cigarettes per day. Analyses were adjusted for age at enrollment (continuous variable), BMI, and alcohol drinking status.

To examine the association between smoking status and adiponectin, stratified by insulin resistance (HOMAIR), BMI, and WC, we divided our study samples into two groups (by median value) of HOMA-IR $(<0.750$ and $\geq 0.750)$, BMI $(<24.2$ and $\geq 24.2)$, and WC $(<84$ and $\geq 84$ ). All analyses were conducted using SAS statistical software, version 9.0 (SAS Institute Inc, Cary, NC). All statistical tests were two-sided, and statistical significance was determined as $\mathrm{p}<0.05$. 
Table 1. General characteristics of the Korean male study population according to smoking status in Seoul, Korea, 2006

\begin{tabular}{|c|c|c|c|c|}
\hline \multirow{3}{*}{$\mathrm{N}$} & \multicolumn{3}{|c|}{ Smoking Status } & \multirow{3}{*}{ P-value } \\
\hline & Non-smokers & Ex-smokers & Current smokers & \\
\hline & $\begin{array}{c}647 \\
\text { Mean } \pm \text { SD }\end{array}$ & $\begin{array}{c}822 \\
\text { Mean } \pm \text { SD }\end{array}$ & $\begin{array}{c}1031 \\
\text { Mean } \pm \text { SD }\end{array}$ & \\
\hline Age, year & $44.5 \pm 8.8$ & $46.8 \pm 9.1$ & $42.8 \pm 7.9$ & $<0.0001$ \\
\hline $\mathrm{WC}, \mathrm{cm}$ & $83.3 \pm 6.9$ & $85.3 \pm 6.9$ & $84.6 \pm 7.5$ & $<0.0001$ \\
\hline BMI, $\mathrm{kg} / \mathrm{m}^{2}$ & $24.0 \pm 2.5$ & $24.6 \pm 2.4$ & $24.4 \pm 2.8$ & $<0.0001$ \\
\hline Adiponectin, $\mu \mathrm{g} / \mathrm{ml}$ & $7.3 \pm 4.4$ & $7.0 \pm 3.8$ & $6.6 \pm 3.7$ & 0.0010 \\
\hline Log Adiponectin, $\mu \mathrm{g} / \mathrm{ml}$ & $2.5 \pm 0.6$ & $2.5 \pm 0.5$ & $2.4 \pm 0.6$ & 0.0006 \\
\hline FBS, $\mathrm{mg} / \mathrm{dL}$ & $90.7 \pm 9.1$ & $92.2 \pm 9.6$ & $91.1 \pm 9.5$ & 0.0048 \\
\hline $\mathrm{SBP}, \mathrm{mmHg}$ & $119.7 \pm 10.5$ & $119.9 \pm 11.6$ & $118.5 \pm 10.4$ & 0.0090 \\
\hline $\mathrm{DBP}, \mathrm{mmHg}$ & $74.8 \pm 8.0$ & $75.0 \pm 8.0$ & $73.5 \pm 7.9$ & $<0.0001$ \\
\hline HDL cholesterol, $\mathrm{mg} / \mathrm{dL}$ & $50.6 \pm 10.9$ & $50.7 \pm 11.1$ & $48.8 \pm 10.9$ & 0.0001 \\
\hline LDL cholesterol, $\mathrm{mg} / \mathrm{dL}$ & $113.1 \pm 28.2$ & $116.5 \pm 26.3$ & $116.3 \pm 30.1$ & 0.0394 \\
\hline Triglyceride, $\mathrm{mg} / \mathrm{dL}$ & $119.2 \pm 67.1$ & $139.5 \pm 95.0$ & $151.3 \pm 104.9$ & $<0.0001$ \\
\hline C-reactive protein, $\mathrm{mg} / \mathrm{dL}$ & $0.15 \pm 0.3$ & $0.16 \pm 0.4$ & $0.15 \pm 0.2$ & 0.7646 \\
\hline \multirow[t]{2}{*}{ HOMA } & $0.9 \pm 0.6$ & $1.0 \pm 0.7$ & $0.9 \pm 0.7$ & 0.0012 \\
\hline & $\%$ & $\%$ & $\%$ & \\
\hline Family history of diabetes & 18.0 & 15.9 & 14.0 & 0.0752 \\
\hline Alcohol drinking & 80.8 & 90.0 & 93.2 & $<0.0001$ \\
\hline
\end{tabular}

$\mathrm{P}$-value refers to differences between groups as determined by ANOVA and $\mathrm{X}^{2}$ test for continuous and categorical variables, respectively.

FBS: fasting blood sugar, BMI: body mass index, WC: waist circumference, SBP: systolic blood pressure, DBP: diastolic blood pressure, HOMA: homeostasis model assessment, HDL: high density lipoprotein, LDL: low density lipoprotein

Table 2. Age-adjusted Pearson correlation coefficients between serum adiponectin and clinical parameters in Korean men in Seoul, Korea, 2006

\begin{tabular}{lcc}
\hline & \multicolumn{2}{c}{ Subjects $(\mathrm{n}=2500)$} \\
\cline { 2 - 3 } & $\mathrm{r}$ & $\mathrm{P}$ \\
\hline $\mathrm{BMI}, \mathrm{kg} / \mathrm{m}^{2}$ & -0.1930 & $<0.0001$ \\
$\mathrm{WC}, \mathrm{cm}$ & -0.2236 & $<0.0001$ \\
$\mathrm{FBS}, \mathrm{mg} / \mathrm{dL}$ & -0.1690 & $<0.0001$ \\
$\mathrm{SBP}, \mathrm{mmHg}$ & -0.1168 & $<0.0001$ \\
DBP, mmHg & -0.0170 & 0.4023 \\
HDL cholesterol, mg/dL & 0.2307 & $<0.0001$ \\
LDL cholesterol, mg/dL & -0.0114 & 0.5736 \\
Triglyceride, mg/dL & -0.1554 & $<0.0001$ \\
C-reactive protein, mg/dL & -0.0201 & 0.3228 \\
HOMA & -0.1666 & $<0.0001$ \\
\hline
\end{tabular}

FBS: fasting blood sugar, BMI: body mass index, WC: waist circumference, SBP: systolic blood pressure, DBP: diastolic blood pressure, HOMA: homeostasis model assessment, HDL: high density lipoprotein, LDL: low density lipoprotein

\section{Results}

The characteristics of participants in relation to their
Table 3. Multiple linear regression model of mean log adiponectin levels in healthy Korean men in Seoul, Korea, 2006

\begin{tabular}{llrrrr}
\hline \multirow{2}{*}{ Variables } & \multicolumn{2}{c}{ Model 1 } & \multicolumn{2}{c}{ Model 2 } \\
\cline { 3 - 6 } & & $\beta$ & P value & $\beta$ & P value \\
\hline Age, year & & 0.005 & 0.0001 & 0.004 & 0.0040 \\
Smoking status & Ex & -0.038 & 0.1889 & -0.002 & 0.9397 \\
& Current & -0.089 & 0.0012 & -0.064 & 0.0190 \\
BMI, kg/m2 & & & & -0.042 & $<0.0001$ \\
Alcohol drinking & & & & -0.085 & 0.0142 \\
\hline
\end{tabular}

BMI: body mass index

smoking status are shown in Table 1. The mean age differed significantly according to smoking status. Current smokers were the youngest and ex-smokers the oldest. Mean adiponectin concentrations were $6.6 \mu \mathrm{g} / \mathrm{ml}$ and $7.3 \mu \mathrm{g} / \mathrm{ml}$ in current smokers and nonsmokers, respectively. C-reactive protein levels were not associated with smoking status $(\mathrm{P}=0.7646)$. Alcohol consumption were associated with smoking status in that current or ex-smokers were more likely to consume alcohol frequently. 
Table 4. Multiple linear regression model ${ }^{*}$ of mean log adiponectin levels according to HOMA, BMI, and WC in healthy Korean men in Seoul, Korea, 2006

\begin{tabular}{|c|c|c|c|c|c|c|c|c|}
\hline \multirow{2}{*}{ Variables } & \multirow{2}{*}{ Subgroups } & \multirow[t]{2}{*}{$\mathrm{N}$} & \multicolumn{2}{|c|}{$\begin{array}{l}\text { Light smokers } \\
\text { (1-9/day) }\end{array}$} & \multicolumn{2}{|c|}{$\begin{array}{l}\text { Moderate smokers } \\
\qquad(10-19 / \text { day })\end{array}$} & \multicolumn{2}{|c|}{$\begin{array}{l}\text { Heavy smokers } \\
\text { ( } \geq 20 / \text { day })\end{array}$} \\
\hline & & & $\beta$ & $P$ value & $\beta$ & $P$ value & $\beta$ & $\mathrm{P}$ value \\
\hline \multirow{3}{*}{ HOMA } & All & 2500 & -0.001 & 0.9891 & -0.030 & 0.4375 & -0.095 & 0.0028 \\
\hline & $<0.750$ & 1249 & 0.083 & 0.2729 & -0.089 & 0.0981 & -0.090 & 0.0432 \\
\hline & $\geq 0.750$ & 1251 & -0.062 & 0.3677 & 0.031 & 0.5692 & -0.101 & 0.0292 \\
\hline \multirow[t]{2}{*}{ BMI, kg/m2 } & $<24.2$ & 1252 & 0.069 & 0.3304 & -0.066 & 0.2044 & -0.110 & 0.0124 \\
\hline & $\geq 24.2$ & 1248 & -0.077 & 0.2996 & -0.001 & 0.9961 & -0.087 & 0.0629 \\
\hline \multirow[t]{2}{*}{$\mathrm{WC}, \mathrm{cm}$} & $<84$ & 1138 & 0.112 & 0.1473 & -0.033 & 0.5331 & -0.076 & 0.0967 \\
\hline & $>=84$ & 1362 & -0.074 & 0.2817 & -0.039 & 0.4809 & -0.108 & 0.0147 \\
\hline
\end{tabular}

Adjusted for age, BMI, and alcohol drinking.

BMI: body mass index, WC: waist circumference, HOMA: homeostasis model assessment

* Reference group: non-smokers

Levels of adiponectin were inversely associated with BMI, WC, and triglycerides, while directly associated with HDL cholesterol $(\mathrm{P}<0.001)$ (Table 2). Mean log adiponectin levels were decreased by 0.089 $\mu \mathrm{g} / \mathrm{ml}$ in current smokers compared with non-smokers after adjusting for age $(\mathrm{P}=0.0012)$, and decreased by $0.064 \mu \mathrm{g} / \mathrm{ml}$ after adjusting for age, BMI, and alcohol drinking $(\mathrm{P}=0.0190)$ (Table 3$)$.

Current smokers were grouped according to the quantity of cigarettes smoked per day $(1-10,11-20,20$ or more) in order to examine the relationship between smoking intensity and adiponectin levels (Table 4). Mean $\log$ adiponectin levels decreased by 0.030 and $0.095 \mu \mathrm{g} / \mathrm{ml}$ in moderate smokers and heavy smokers, respectively, in comparison to non-smokers. The ageadjusted Pearson correlation coefficient between serum adiponectin and the number of cigarettes/day was also -0.0597 and statistically significant $(p=0.0087)$ (data not shown). Next, to control potential confounding by insulin resistance and obesity, the data were further stratified by BMI, WC, and HOMA (Table 4). The relationship between adiponectin and smoking was similar among insulin resistance (HOMA) groups. When compared to non-smokers, mean log adiponectin levels decreased by $0.090 \mu \mathrm{g} / \mathrm{ml}$ and $0.101 \mu \mathrm{g} / \mathrm{ml}$ in both heavy smokers with HOMA $<0.750$ ( $\mathrm{p}$-value $=0.0432)$ and with $\operatorname{HOMA} \geq 0.750(\mathrm{p}$ value $=0.0292)$, respectively. Similar associations of adiponectin levels with smoking status were seen in the BMI and WC groups.

\section{Discussion}

Our study demonstrates that smoking status is associated with lower levels of adiponectin, which supports findings of previous studies [9-13]. In a recent study in a healthy Japanese population, a significant dose-response relationship was found between the number of cigarettes and adiponectin concentrations in men [9]. The present study also showed a dosedependent relationship between smoking amounts and adiponectin levels in Korean men. The relationship remained even in subgroup analyses by HOMA-IR.

Because the prevalence of insulin resistance is increased in smokers $[14,15]$, reports of lower adiponectin concentrations in smokers may not be related to smoking, but to the concomitant presence of insulin resistance in smokers [10]. However, in a recent cross-sectional study consisting of 30 smokers and 30 non-smokers, the difference in mean adiponectin concentrations between smokers and non-smokers did not depend on the insulin resistance statuses of the subjects [10]. Since the study by Abbasi used a small sample size, with a bigger population we also looked at the association between adiponectin and smoking. We also found that the lower plasma adiponectin concentrations in smokers were not dependent on the insulin resistance statuses of the subjects. These results support that reports of lower adiponectin concentrations in smokers may be related to smoking, not to the concomitant presence of insulin resistance in smokers.

Cigarette smoke contains a large amount of free radicals, resulting in endothelial injury. Oxidative 
stress can damage many cell components, including DNA, lipid membranes, and proteins, and may lead to apoptosis and cell damage $[17,18]$. On the other hand, nicotine, a major component of cigarette smoke, promotes inflammation and has a direct effect on human adipose tissue $[19,20]$. In a study using cultured mouse 3T3-L1 adipocytes, Iwashma et al. [11] reported that $\mathrm{H}_{2} \mathrm{O}_{2}$ and nicotine reduced mRNA expression and secretion of adiponectin in a dose-dependent manner. This provides a biologically plausible explanation for our findings in that we also observed a doseresponse relationship between smoking amounts and adiponectin.

However, in contrast to the impact of smoking on serum adiponectin concentrations, $\mathrm{C}$-reactive protein (CRP) concentrations were not associated with smoking status in the present study. Some previous studies have suggested an adverse effect of smoking on CRP concentration [21, 22]. However, recent cross-sectional studies found no difference of plasma CRP levels between smokers and non-smokers, as seen in our study $[10,23]$.

The main strength of our study is that to our knowledge this may be the first study enrolling a large number of healthy individuals that examined associations between serum adiponectin levels and smoking, while taking into consideration insulin resistance and obesity. This study has also several limitations. Due to its cross-sectional design, this study cannot elucidate mechanisms or determine the direction of causality. A single assessment of adiponectin levels may be suscep- tible to short-term variation, which would bias the results toward the null. Another limitation is that this study was done in only men because there are few female smokers in Korea. However, Pischon et al. [24] reported that intra-individual adiponectin levels are reasonably stable over time, with an intra-class correlation coefficient of 0.85 for adiponectin levels measured within the same participants one year apart.

In conclusion, our findings suggest that adiponectin concentrations are lower in smokers, and this association may not be due to the concomitant presence of insulin resistance and obesity. Further studies including other populations such as women or other ethnic groups should be performed to confirm the association between adiponectin and smoking status regardless of insulin resistance.

\section{Acknowledgments}

This study was funded by the Seoul City R\&BD program (10526).

\section{Appendix}

List of participating hospitals in Korean Metabolic Syndrome Research Initiatives:

Severance Hospital, Yonsei University; Ewha Women's University; Seoul National University; Korea University.

\section{References}

1. Stefan N, Vozarova B, Funahashi T, Matsuzawa Y, Weyer C, Lindsay RS, Youngren JF, Havel PJ, Pratley RE, Bogardus C, Tataranni PA (2002) Plasma adiponectin concentration is associated with skeletal muscle insulin receptor tyrosine phosphorylation, and low plasma concentration precedes a decrease in wholebody insulin sensitivity in humans. Diabetes 51: 18841888.

2. Bacci S, Menzaghi C, Ercolino T, Ma X, Rauseo A, Salvemini L, Vigna C, Fanelli R, Di Mario U, Doria A, Trischitta V (2004) The $+276 \mathrm{G} / \mathrm{T}$ single nucleotide polymorphism of the adiponectin gene is associated with coronary artery disease in type 2 diabetic patients. Diabetes Care 27: 2015-2020.

3. Kita A, Yamasaki H, Kuwahara H, Moriuchi A, Fukushima K, Kobayashi M, Fukushima T, Takahashi
R, Abiru N, Uotani S, Kawasaki E, Eguchi K (2005) Identification of the promoter region required for human adiponectin gene transcription: Association with CCAAT/enhancer binding protein-beta and tumor necrosis factor-alpha. Biochem Biophys Res Commun 331: 484-490.

4. Fasshauer M, Klein J, Neumann S, Eszlinger $M$ and Paschke R (2002) Hormonal regulation of adiponectin gene expression in 3T3-L1 adipocytes. Biochem Biophys Res Commun 290: 1084-1089.

5. Filippi E, Sentinelli F, Trischitta V, Romeo S, Arca M, Leonetti F, Di Mario U, Baroni MG (2004) Association of the human adiponectin gene and insulin resistance. Eur J Hum Genet 12: 199-205.

6. Yamauchi T, Kamon J, Waki H, Terauchi Y, Kubota N, Hara K, Mori Y, Ide T, Murakami K, Tsuboyama- 
Kasaoka N, Ezaki O, Akanuma Y, Gavrilova O, Vinson C, Reitman ML, Kagechika H, Shudo K, Yoda M, Nakano Y, Tobe K, Nagai R, Kimura S, Tomita M, Froguel P and Kadowaki T (2001) The fat-derived hormone adiponectin reverses insulin resistance associated with both lipoatrophy and obesity. Nat Med 7: 941-946.

7. Hotta K, Funahashi T, Arita Y, Takahashi M, Matsuda M, Okamoto Y, Iwahashi H, Kuriyama H, Ouchi N, Maeda K, Nishida M, Kihara S, Sakai N, Nakajima T, Hasegawa K, Muraguchi M, Ohmoto Y, Nakamura T, Yamashita S, Hanafusa T, Matsuzawa Y (2000) Plasma concentrations of a novel, adipose-specific protein, adiponectin, in type 2 diabetic patients. Arterioscler Thromb Vasc Biol 20: 1595-1599.

8. Diez JJ and Iglesias P (2003) The role of the novel adipocyte-derived hormone adiponectin in human disease. Eur J Endocrinol 148: 293-300.

9. Takefuji S, Yatsuya H, Tamakoshi K, Otsuka R, Wada K, Matsushita K, Sugiura K, Hotta Y, Mitsuhashi H, Oiso Y, Toyoshima H (2007) Smoking status and adiponectin in healthy Japanese men and women. Prev Med 45: 471-475.

10. Abbasi F, Farin HM, Lamendola C, McLaughlin T, Schwartz EA, Reaven GM, Reaven PD (2006) The relationship between plasma adiponectin concentration and insulin resistance is altered in smokers. $J$ Clin Endocrinol Metab 91: 5002-5007.

11. Iwashima Y, Katsuya T, Ishikawa K, Kida I, Ohishi M, Horio T, Ouchi N, Ohashi K, Kihara S, Funahashi T, Rakugi H, Ogihara T (2005) Association of hypoadiponectinemia with smoking habit in men. Hypertension 45: 1094-1100.

12. Miyazaki T, Shimada K, Mokuno H, Daida H (2003) Adipocyte derived plasma protein, adiponectin, is associated with smoking status in patients with coronary artery disease. Heart 89: 663-664.

13. Thamer C, Stefan N, Stumvoll M, Häring H, Fritsche A (2005) Reduced adiponectin serum levels in smokers. Atherosclerosis 179: 421-422.

14. Facchini FS, Hollenbeck CB, Jeppesen J, Chen YD,
Reaven GM (1992) Insulin resistance and cigarette smoking. Lancet 339: 1128-1130.

15. Attvall S, Fowelin J, Lager I, Von Schenck H, Smith U (1993) Smoking induces insulin resistance - a potential link with the insulin resistance syndrome. J Intern Med 233: 327-332.

16. Yoon SJ, Lee HS, Lee SW, Yun JE, Kim SY, Cho E, Lee SJ, Lee EJ, Lee HY, Park J, Kim HS, Jee SH (2008) The association between adiponectin and diabetes in the Korean population. Metabolism 57: 853-857.

17. Freeman BA, Crapo JD (1982) Biology of disease: free radicals and tissue injury. Lab Invest 47: 412-426.

18. Papa S, Skulachev VP (1997) Reactive oxygen species, mitochondria, apoptosis and aging. Mol Cell Biochem 174: 305-319.

19. Andersson K, Arner P (1995) Cholinoceptor-mediated effects on glycerol output from human adipose tissue using in situ microdialysis. Br J Pharmacol 115: 11551162.

20. Andersson K, Arner P (2001) Systemic nicotine stimulates human adipose tissue lipolysis through local cholinergic and catecholaminergic receptors. Int $J$ Obes Relat Metab Disord 25: 1225-1232.

21. Bermudez EA, Rifai N, Buring JE, Manson JE, Ridker PM (2002) Relation between markers of systemic vascular inflammation and smoking in women. $\mathrm{Am} \mathrm{J}$ Cardiol 89: 1117-1119.

22. Tracy RP, Psaty BM, Macy E, Bovill EG, Cushman M, Cornell ES, Kuller LH (1997) Lifetime smoking exposure affects the association of C-reactive protein with cardiovascular disease risk factors and subclinical disease in healthy elderly subjects. Arterioscler Thromb Vasc Biol 17: 2167-2176.

23. Sonmez A, Dogru T, Yilmaz MI, Tasci I, Ocal R, Ozgurtas T, Kilic S, Erbil K, Erikci S, Tsao P (2006) Adiponectin and insulin resistance in young and healthy smokers. Endocr J 53: 729-734.

24. Pischon T, Hotamisligli GS, Rimm EB (2003) Adiponectin: stability in plasma over 36 hours and withinperson variation over 1 year. Clin Chem 49: 650-652. 